\title{
SPORE ANTIGENS IN THE CLASSIFICATION OF SOME CLOSTRIDIA
}

\author{
T. J. T. PRINCEWILL* \\ Department of Microbiology, Agricultural Science Buildings, The University, Leeds LS2 9JT
}

\begin{abstract}
ALTHOUGH Clostridium sporogenes and C. histolyticum show obvious cultural and biochemical differences, several workers have adduced evidence for the sharing of vegetative and spore antigens by these two species (Smith, 1937; Mandia, 1955; Meisel and Rymkiewicz, 1959; Lynt, Solomon and Kautter, 1972). In their attempts to classify the proteolytic clostridia by means of vegetative antigens, Mandia $(1951 ; 1952 a ; 1952 b ; 1955)$ and Mandia and Bruner (1951) did not include C. bifermentans which is an important proteolytic species. Meisel and Rymkiewicz (1959) showed that the spore antigens of this organism did not cross-react with spore antigens of the other proteolytic species they studied. However, cross reactions were reported by Walker (1963) between the spore antigens of $C$. bifermentans and $C$. sordelli, which are closely related species (Brooks and Epps, 1959). Princewill (1979) used the spore antigens to serotype strains of $C$. sporogenes. That study has now been extended to investigate the taxonomic relationship between $C$. sporogenes, $C$. histolyticum, C. bifermentans and C. butyricum.
\end{abstract}

\section{MATERIALS AND METHODS}

Strains of clostridia. The 84 strains of $C$. sporogenes used in this study and their origin have been described elsewhere (Princewill, 1978). The 69 strains of C. histolyticum were: nos. 119, 294, 646 from Dr H. Meisel, Serum Research Institute, Warsaw, Poland; CN nos. 919, 920, 948, $949,950,1693,3056,3252,3254,3255,3256,3257,3258,3259,3260,3261,3265$, 3266, 3267, $3268,3269,3270,3271,3272,3273,3274,3276,3277,3278,3279,3280,3281,3282$, 3283, 3284, $3285,3286,3287,3288,3289,3290,3292,3293,3294,3295,3296,3297,3298,3300,3301,3302$, $3303,3304,3305,3306,3307,3308,3309,3310,3311,3312,3313,3786,4760,6304$ from the Wellcome Research Laboratories, Langley Court, Beckenham, Kent; and from The National Collection of Industrial Bacteria no. NCIB503, Torrey Research Station (NCIB), Aberdeen. Other species were: $C$. bifermentans NCIB strains nos. 506, 2912, 2929, 6800, 6928 from NCIB; C. beijerinckii no. NCIB9362 from NCIB; $C$. tyrobutyricum no. CNRZ500 and C. saccharobutyricum no. CNRZ555 from Dr J. L. Bergère, INRA, Jouy-en-Josas, France; $C$. butyricum no. CNRZ5328 from Dr Bergère, and C. butyricum no. SA II from Dr J. W. Classens, Bloemfontein, South Africa.

Lyophilised cultures were reconstituted, grown in cooked-meat medium (CMM from Southern Group Laboratory, Hither Green Hospital, London) and cultured on fresh horse-blood agar. After incubation at $37^{\circ} \mathrm{C}$ for $48 \mathrm{~h}$, single colonies were isolated and their identity was checked by routine methods (Princewill, 1978).

Received 16 Aug. 1978; revised version accepted 27 Feb. 1979.

* Present address: Nigerian Institute for Trypanosomiasis Research, Vom, via Jos, Nigeria.

J. MED. MICROBIOL.- VOL. 12 (1979) 
Some members of the butyric group did not grow in the above media and were cultured in tomato-juice medium (Sarathchandra, 1973), which consisted of tomato puree $6.0 \mathrm{~g}$, Peptone (Oxoid) $10.0 \mathrm{~g}$, Tryptone (Difco) $10.0 \mathrm{~g}$, cysteine hydrochloride $0.5 \mathrm{~g}$, distilled water 1 litre; the $p \mathrm{H}$ was adjusted to $6 \cdot 1$ and the medium was autoclaved at $121^{\circ} \mathrm{C}$ for $15 \mathrm{~min}$.; it was used either liquid or solidified with agar.

Production of spores. The method of producing the spore suspensions was similar to that described by Princewill (1979). The cultures were harvested and sonicated and the spores were freed from the vegetative debris by repeated washings. Clean spore suspensions were then prepared, containing $10^{8}-10^{9}$ spores $/ \mathrm{ml}$ as determined in a counting chamber by phase-contrast microscopy. Spore-antigen suspensions for immunisation were prepared by incubating the clean spore suspensions with formaldehyde $(0 \cdot 2 \% \mathrm{v} / \mathrm{v})$ at $37^{\circ} \mathrm{C}$ for 7 days. The spore antigens were then stored at $4^{\circ} \mathrm{C}$. The antigen for the agglutination test was prepared from the spore-antigen suspensions by washing once with preservative saline-physiological saline containing thiomersal $0.005 \%(\mathrm{w} / \mathrm{v})$ and sodium azide $0.5 \%(\mathrm{w} / \mathrm{v})$ - to remove the formalin.

Precipitation of spore antigens. Acid extracts of spore antigens were prepared by the method of Lamanna (1942); $10 \mathrm{ml}$ of clean spore suspension was centrifuged and the spore sediment was resuspended in $1.0 \mathrm{ml}$ of $0.05 \mathrm{~N} \mathrm{HCl}$ in preservative saline and heated for $10 \mathrm{~min}$. in boiling water. After cooling, the suspension was centrifuged and the $p \mathrm{H}$ of the supernatant was adjusted to 7.0 with $1 \mathrm{~N} \mathrm{NaOH}$ and phenol-red indicator.

Vegetative-cell antigens. Broth cultures were incubated for $18 \mathrm{~h}$ then examined by phasecontrast microscopy to confirm the presence of vegetative cells and the absence of spores. For $\mathrm{H}-\mathrm{O}$ antigens, the cultures were inactivated by incubation with formaldehyde $(0.2 \% \mathrm{v} / \mathrm{v})$ at $37^{\circ} \mathrm{C}$ for 3-4 days; for somatic $(\mathrm{O})$ antigens the cultures were heated at $100^{\circ} \mathrm{C}$ for $1 \mathrm{~h}$, cooled and then preserved with formaldehyde $(0 \cdot 1 \% \mathrm{v} / \mathrm{v})$. Both $\mathrm{H}-\mathrm{O}$ and $\mathrm{O}$ suspensions were adjusted to contain $10^{8}-10^{9}$ vegetative cells $/ \mathrm{ml}$ as described for the spore suspensions.

Spore antisera. Male New Zealand white rabbits $(2-3 \mathrm{~kg})$ were given weekly subcutaneous injections of $1.0 \mathrm{ml}$ of spore-antigen suspensions. Samples of blood were taken before the first injection, on the 3rd and 7th day and at weekly intervals until 3 weeks; 7-10 days later the rabbits were bled and the sera were tested for the presence of agglutinins against the immunising antigens. If satisfactory titres were obtained-at least 800 , except the antiserum to strain 81 of which the titre was 160 - the animals were bled under anaesthetic. The antisera were absorbed with homologous vegetative antigens to remove $\mathrm{H}$ and $\mathrm{O}$ antibodies. Ten $\mathrm{ml}$ of the $\mathrm{H}-\mathrm{O}$ and $\mathrm{O}$ vegetative-cell suspensions were centrifuged; the cell deposit of the $\mathrm{H}-\mathrm{O}$ suspension was resuspended in $1.0 \mathrm{ml}$ of the undiluted serum, incubated in a shaking water bath at $37^{\circ} \mathrm{C}$ for 45 min and then centrifuged. The supernatant serum was absorbed with the cell deposit of the $O$ suspension. If vegetative antibodies were still detected in the serum, the absorptions were repeated until there was no agglutination with the absorbing suspensions.

Agglutination tests. Twofold dilutions of antiserum were prepared in $0 \cdot 1-\mathrm{ml}$ volumes in saline starting from 1 in 10 in Wasserman test tubes. Equal volumes of the appropriate spore-antigen suspension were added and, after mixing, the tubes were incubated in a shaking water bath at 60 shakes $/ \mathrm{min}$. and $37^{\circ} \mathrm{C}$ for $45 \mathrm{~min} . ; 0.8 \mathrm{ml}$ of saline was added to each tube and the agglutination was observed immediately with the aid of a bright light against a black background. The highest dilution showing visible agglutination was taken as the end point. Normal rabbit serum and saline controls were included. (Noble, 1927; Lamanna, 1940; Norris and Wolf, 1961; Walker, 1963).

Fluorescent-antibody technique (FAT). Smears prepared on clean slides from the sporeantigen suspensions used in the agglutination test were dried in air and fixed by gentle heat. The smears were overlayed with one drop of a twofold dilution of spore antiserum and held in a moist chamber for $30 \mathrm{~min}$. at $37^{\circ} \mathrm{C}$. The slides were rinsed, washed twice in $3 \times 10^{-4} \mathrm{M}$ phosphate buffered saline, $p \mathrm{H} \mathrm{7.2}$ for $20 \mathrm{~min}$. and dried in air. Finally, the smears were overlayed with fluorescein-labelled sheep anti-rabbit immunoglobulin (Burroughs Wellcome) diluted 1 in 20, held in a moist chamber as before and then rinsed and washed. The stained smears were dried in air and examined with an M41 Photoplan Fluorescence Microscope (Vickers Instruments Ltd). The intensity of fluorescence was assessed on a scale of - to $4+$; a reaction of $2+$ or greater was scored as positive. 
Precipitation ring test. The acid extract of spore antigens was carefully layered on the antiserum in narrow tubes ( $2 \mathrm{~mm}$ internal diameter) and the results observed at intervals up to $1 \mathrm{~h}$. A precipitation ring usually developed within a few minutes.

\section{RESULTS}

\section{Spore-agglutination tests}

Antisera against two strains of $C$. histolyticum (strains 119 and 646) and one strain each of C. bifermentans (strain NCIB506) and C. butyricum (strain CNRZ528) were diluted 1 in 100, and used in agglutination tests with spore suspensions of each of the 84 strains of $C$. sporogenes, 69 strains of $C$. histolyticum and five strains each of $C$. bifermentans and the butyric group. The seven antisera prepared against the three types of $C$. sporogenes (Princewill 1979) were also included in these tests. The results are shown in table I. None

\section{TABLE I}

Agglutination reactions of spore antisera prepared against strains of Clostridium sporogenes, $C$. histolyticum, C. bifermentans and C. butyricum

\begin{tabular}{|c|c|c|c|c|c|c|c|c|}
\hline \multirow[b]{3}{*}{ Antigen strains } & \multirow{3}{*}{$\begin{array}{l}\text { Number of } \\
\text { strains } \\
\text { tested }\end{array}$} & \multicolumn{7}{|c|}{ Number of strains agglutinating with antisera* against } \\
\hline & & \multicolumn{3}{|c|}{$\begin{array}{l}\text { C. sporogenes } \\
\text { type }\end{array}$} & \multicolumn{2}{|c|}{$\begin{array}{l}\text { C. histolyticum } \\
\text { strain }\end{array}$} & \multirow{2}{*}{$\begin{array}{l}\text { C. bifermentans } \\
\text { strain NCIB506 }\end{array}$} & \multirow{2}{*}{$\begin{array}{l}\text { C. butyricum } \\
\text { CNRZ528 }\end{array}$} \\
\hline & & $\mathrm{I}^{\dagger}$ & II & III & 119 & 646 & & \\
\hline C. sporogenes: I & 66 & 66 & 0 & 0 & 0 & 66 & 0 & 0 \\
\hline type II & 17 & 0 & 17 & 0 & 0 & 0 & 0 & 0 \\
\hline type III & 1 & 0 & 0 & 1 & 0 & 0 & 0 & 0 \\
\hline C. histolyticum & 69 & 0 & 0 & 0 & 69 & 3 & 0 & 0 \\
\hline C. bifermentans & 5 & 0 & 0 & 0 & 0 & 0 & 5 & 0 \\
\hline Butyric group & 5 & 0 & 0 & 0 & 0 & 0 & 0 & 5 \\
\hline
\end{tabular}

* Diluted 1 in 100

† The 5 spore antisera $(2,17,37,75$ and 98$)$ prepared by Princewill (1979) were used.

of the seven C. sporogenes antisera agglutinated the spores of the 69 strains of $C$. histolyticum and the five strains each of $C$. bifermentans and the butyric group. Furthermore, there were no cross reactions between the three types of $C$. sporogenes. One of the antisera prepared against $C$. histolyticum (strain 119) agglutinated all the 69 strains of that species; the other antiserum (strain 646) reacted only with the homologous strain and two other strains. On the other hand, this latter antiserum reacted with spores of the 66 strains of $C$. sporogenes type I but not with spores of types II and III. The antisera prepared against $C$. bifermentans (strain NCIB506) and C. butyricum (strain CNRZ528) reacted only with strains of the homologous species and showed no cross reactions.

To determine the extent of the sharing of spore antigens between $C$. sporogenes type I and $C$. histolyticum, the agglutinins in the antisera were absorbed and titrated. The results (table II) showed that in general the 


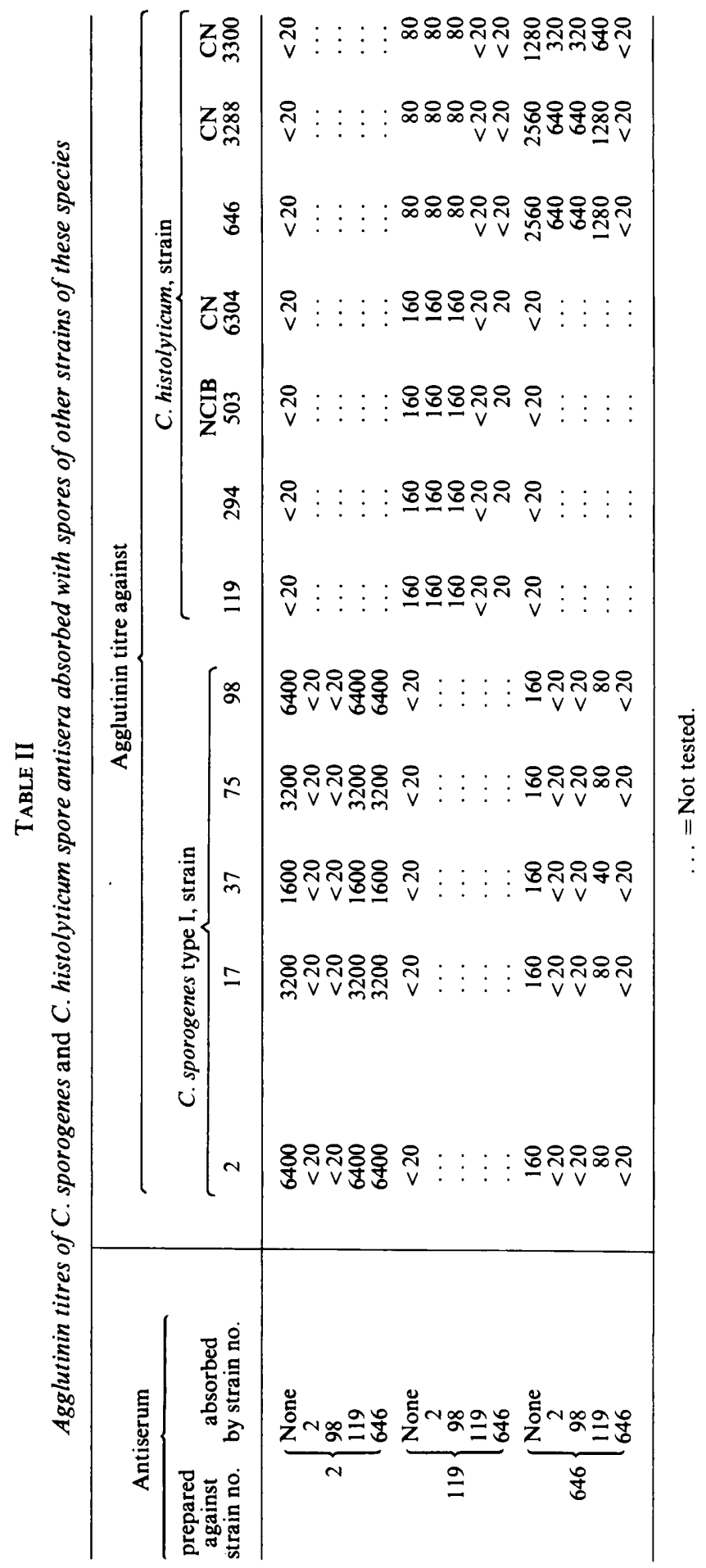


antigens were species specific; the only cross reaction occurred with antiserum prepared against $C$. histolyticum strain 646, which agglutinated spores of some strains of $C$. sporogenes type I to a relatively low titre (160). Absorption of this antiserum with spores of $C$. sporogenes type I strains 2 and 98 removed these antibodies and absorption with $C$. histolyticum strain 119 also slightly reduced the titre against the homologous strain. In addition, there was a distinct difference between strains 119 and 646 of $C$. histolyticum; the antiserum prepared against 119 agglutinated the spores of all strains of $C$. histolyticum tested (table I), but this strain did not react with antiserum against strain 646 which agglutinated spores of only three strains of $C$. histolyticum $(646, \mathrm{CN} 3288$ and CN3300).

Absorption of antiserum against strain 646 with spores of strain 119 did not remove the antibody. On the other hand, absorption of antiserum against strain 119 with spores of strain 646 removed all the antibodies reacting with it and with the other two strains (CN3288 and CN3300), but did not remove all the antibodies reacting with the homologous strain (119) or with three other strains (294, NCIB503 and CN6304). A low level of antibody was left even after repeated absorptions. This suggests that there are at least two types of $C$. histolyticum; type I represented by strain 119 and type II by strain 646 which cross reacted with $C$. sporogenes type I.

To detect whether cross reactions occurred at low titres of antisera among strains of $C$. sporogenes, $C$. bifermentans and the butyric group, quantitative agglutination tests were performed. The results are presented in table III. There was no cross reaction among the three species of Clostridium. The only cross reactions were at low titres $(20-40)$ among the three types of $C$. sporogenes.

\section{Fluorescent-antibody technique ( FAT)}

To examine whether the antisera giving negative results in spore-agglutination tests contained incomplete antibodies, spores of the strains of the other four species were treated with the antisera and the indirect FAT was applied. The results were similar to those of the agglutination tests; the only difference was a positive fluorescence given by spores of strain $\mathrm{CN} 3288$ of $C$. histolyticum with antisera to strains of $C$. sporogenes type I.

\section{Precipitation reactions}

To study the taxonomic significance of spore precipitinogens among strains of $C$. sporogenes, $C$. histolyticum, $C$. bifermentans and the butyric group, acid spore extracts were tested against the spore antisera in the capillary-tube (ring) test. The results showed complete species specificity with no inter-species cross reactions among the four groups.

The only cross reactions were among the different types of $C$. sporogenes and $C$. histolyticum. This confirms once more the taxonomic value of the spore precipitinogens (Norris and Wolf, 1961; Princewill, 1979). 
TABLE III

Agglutination of titres of spore antisera against various strains of $C$. sporogenes, $C$. bifermentans and C. butyricum

\begin{tabular}{cc|ccccc}
\hline & & \multicolumn{3}{|c}{ Agglutinin titre, in tests against the stated spore antigen, of antisera } \\
raised against
\end{tabular}

\section{Discussion}

The differentiation of $C$. sporogenes from $C$. histolyticum is based on their cultural and biochemical characters. However, several reports cite a serological relationship involving their $\mathbf{H}$ (Mandia and Bruner, 1951), $\mathrm{O}$ (Lynt et al., 1972) and spore antigens (Meisel and Rymkiewicz, 1959). A comparison of the spore antigens of $C$. sporogenes and $C$. histolyticum therefore was considered relevant. The two strains of $C$. histolyticum selected for the production of antisera were two of the three strains used by Meisel and Rymkiewicz (1959) in their classical study of the spore agglutination of seven proteolytic Clostridium species; in that investigation, the only cross reaction was between $C$. sporogenes and $C$. histolyticum; these workers also found evidence for the existence of at least three types of $C$. histolyticum. In general, our results agree with theirs, that there is a cross reaction between $C$. sporogenes and $C$. histolyticum on the basis of spore agglutination; there is also evidence of more than one type of $C$. histolyticum.

The antisera prepared against $C$. histolyticum strains 119 and 646 behaved differently in tests with spores of $C$. sporogenes (see table I). Antiserum against strain 119 was species specific, reacting only with 69 strains of $C$. 
histolyticum, whilst antiserum against strain 646 reacted with all the 66 strains of $C$. sporogenes type I and only with three of the strains (646, CN3288 and $\mathrm{CN} 3300$ ) of $C$. histolyticum. This result emphasises the importance of the selection of strains for immunological studies.

For an inter-species study strain 646 is a valuable organism, whereas it is of little value for studying the relationship between strains of $C$. histolyticum. On the other hand, if strain 119 alone had been selected, the cross reaction between $C$. sporogenes and $C$. histolyticum would not have been demonstrated; the antigens of strain 119 are, however, more widely distributed among the strains of $C$. histolyticum than those of strain 646.

Cross-absorption tests revealed the existence of at least three types of spore antigens in strains of $C$. histolyticum (see table II). The species can therefore, be divided into two types: type I, exemplified by strain 119, possesses two antigenic components, one of which (E) determines the type specificity whilst the other $(F)$ is shared by all strains of the species. The designation of these components follows the sequence of the spore antigenic components $\mathrm{A}, \mathrm{B}, \mathrm{C}$ and $\mathrm{D}$ of $C$. sporogenes reported by Princewill (1979). Type II, represented by strain 646, also possesses two antigens: the group component $(F)$ is shared by all strains, and an additional factor $(\mathrm{G})$ is responsible for the cross reaction with strains of $C$. sporogenes type $\mathrm{I}$. Component $(\mathrm{G})$ is also present in strains of $C$. sporogenes type I, but it failed to elicit the production of spore antibodies as shown by the non-reactivity of antisera prepared against $C$. sporogenes type I with the strains of $C$. histolyticum. This was presumably because of either its haptenic nature or of steric factors. A one-way cross reaction between $C$. sporogenes and $C$. histolyticum was also observed by Mandia and Bruner (1951) and Mandia (1952b) in their studies on the vegetative antigens of proteolytic clostridia. Although such one-way reactions might be attributable to the presence of incomplete antibody, the results of the FAT in the present study do not bear this out.

C. bifermentans can be identified by cultural and biochemical tests, but in this investigation an attempt was made to classify it within the serological scheme of the proteolytic clostridia. The antiserum (against strain 646) that was used indicated that the organism had no serological relationship with the strains of $C$. sporogenes examined by means of spore agglutination, FAT and precipitation. Indeed, $C$. bifermentans showed no cross reaction with any of the other species of Clostridium studied and the results indicate that the five strains of $C$. bifermentans form a single type; this confirms the findings of Meisel and Rymkiewicz (1959) and Walker (1963). The number of strains examined in this study was small but the results appear to be due to the presence of a single antigenic component $(\mathrm{J})$ shared by spores of strains of $C$. bifermentans tested. ' $\mathrm{H}$ ' and 'I' have been omitted from the nomenclature of the spore antigens to avoid confusion with flagellar antigen $(\mathrm{H})$ and the Roman numeral (I).

C. butyricum and other members of the butyric group can also be identified by cultural and biochemical tests; they were included in this study as non-proteolytic organisms and as type species of the genus. As in the case of $C$. 
bifermentans, the antiserum against spores of $C$. butyricum strain CNRZ528 was species specific. There was no cross reaction in the spore agglutination, FAT or precipitation tests with strains of $C$. sporogenes or with the other species of Clostridium examined. Although only five members of the butyric group were examined, we conclude that there is a single antigenic component (K) which is shared by spores of all the strains tested. The five strains studied therefore form a single group; this finding agrees with those of other workers who studied the serological relationship among members of $C$. butyricum with respect to the $\mathrm{H}$ and $\mathrm{O}$ antigens (McCoy and McClung, 1938).

\section{SUMMARY}

The spore antigens of Clostridium sporogenes, $C$. histolyticum, C. bifermentans and the butyric group were compared. By spore agglutination and fluorescent-antibody technique (FAT) the 69 strains of $C$. histolyticum were divided into two types: serum raised against type I (66 strains) reacted with all strains of this species but showed no cross reaction with any of the three types of $C$. sporogenes; serum raised against type II (three strains) did not react with strains of $C$. histolyticum type I but showed cross reaction with all the 66 strains of $C$. sporogenes type I. Thus, by antigenic analysis, spores of $C$. histolyticum type I were found to possess two components designated $E$ and $F$; $E$ was a type-specific component whilst $F$ was shared by strains of type II. In addition, strains of $C$. histolyticum type II possessed a second component, $\mathrm{G}$, which was shared by strains of $C$. sporogenes type $\mathrm{I}$. There was no cross reaction between the precipitinogens of the spores of the two species. Five strains of $C$. bifermentans formed a homogeneous group as judged by spore agglutination, FAT and precipitation reactions. There was no cross reaction with any of the other proteolytic species studied. Five butyric strains also formed a homogeneous group. Two antigenic components were therefore assigned to the spore antigens of the two groups: $\mathrm{J}$, for $C$. bifermentans and $\mathrm{K}$, for the butyric strains.

This work was supported in part by a scholarship awarded by the Nigerian Federal Ministry of Education. The author also wishes to thank $\mathrm{Mr} \mathrm{J}$. Wolf for his suggesting the problem and for his invaluable advice and help throughout this investigation.

\section{REFERENCES}

Brooks, M. E. AND EpPS, H. B. G. (1959). Taxonomic studies of the genus Clostridium: Clostridium bifermentans and C. sordellii. J. gen. Microbiol., 21, 144.

Lamanna, C. (1940). The taxonomy of the genus Bacillus. II. Differentiation of small-celled species by means of spore antigens. J. infect. Dis., 67, 193.

LamanNa, C. (1942). The status of Bacillus subtilis, including a note on the separation of precipitinogens from bacterial spores. J. Bact., 44,611.

Lynt, R. K., Solomon, H. M. and KautTer D. A. (1972). Specificity of somatic antisera for detection of Clostridium botulinum by immunofluorescence. Spores V. In Proceedings of 5th International Spore Conference, Am. Soc. Microbiol, Washington, p. 344. 
MCCoy, E. AND MCCLung, L. S. (1938). Serological relations among spore-forming anaerobic Bacteria. Bact. Rev., 2, 47.

Mandia, J. W. (1951). Serological group II of the proteolytic clostridia. J. Immunol., 67, 49.

Mandia, J. W. (1952a). The serological identification of cultures of Clostridium histolyticum as group III of the proteolytic clostridia. J. infect. Dis., 90, 48.

MANDIA, J. W. (1952b). The role of heat-stable antigen in serological identification of proteolytic clostridia. J. Immunol., 69, 451.

Mandia, J. W. (1955). The position of Clostridium tetani within the serological schema for the proteolytic clostridia. J. infect. Dis. 97, 66.

Mandia, J. W. AND BRUNER, D. W. (1951). The serological identification of cultures of Clostridium sporogenes. J. Immunol., 66, 497.

MeISEL, H. AND R YMKIEWICZ, D. (1959). Antygeny zarodnikowe, W Klasyfikacji proteolitycznych clostridia. Medycyna dośw. Mikrobiol., 11, 1.

NoBLE, A. (1927). A rapid method for the macroscopic agglutination test. J. Bact., 14, 287.

NORRIS, J. R. AND WOLF, J. (1961). A study of antigens of the aerobic spore-forming bacteria. J. appl. Bact., 24, 42.

PrinCEWILL, T. J. T. (1978). Differences in colony morphology and carbohydrate fermentation of Clostridium sporogenes. J. gen. Microbiol., 108, 315.

PrinCEWILL, T. J. T. (1979). Spore antigens of Clostridium sporogenes. J. med. Microbiol., 12, 29.

SaRathChandRa, S. U. (1973). Some factors affecting the germination of spores of some Clostridium species. Ph.D Thesis, University of Leeds.

Sмiтh, L. (1937). Some serological aspects of the S-R change in Clostridium histolyticum. J. Bact., 34, 409.

WalKer, P. D. (1963). The spore antigens of Clostridium sporogenes, $\mathrm{Cl}$. bifermentans and $\mathrm{Cl}$. sordellii. J. Path. Bact., 85, 41. 